\title{
Megaproyectos y conflictos ecoterritoriales. El caso del Tren Maya
}

\author{
Laura Casanova Casañas*
}

\section{RESUMEN}

Al amparo de la globalización neoliberal, actualmente los procesos de despojo transforman de manera recurrente territorios indígenas en América Latina. En este artículo, se propone analizar la oposición que se da entre estas prácticas de acumulación por desposesión de las empresas transnacionales (ETN) y las cosmovisiones de los pueblos originarios a través del análisis de los conflictos ecoterritoriales. Tomando el concepto de Rocío Silva Santisteban, se trata de conflictos que nacen de la pugna por el uso y gestión del territorio, entendiendo territorio como concepto holístico, donde interaccionan múltiples violencias. El objetivo de este artículo será desgranar el choque entre estas dos visiones antagónicas del mundo de la mano de perspectivas como la ecología-mundo de Jason W. Moore, que permitirá leer los megaproyectos como un producto más del capitalismo que explota sistémicamente seres humanos y naturaleza al servicio de la acumulación, o el ecofeminismo, que aportará luz a la interdependencia entre territorios y cuerpos como espacios vulnerables.

Asimismo, se tomará como ejemplo el caso del Tren Maya, el megaproyecto estrella del actual presidente de México, Andrés Manuel López Obrador, para evidenciar el falso desarrollo que promete la obra ferroviaria para el sureste del país en el marco de la llamada Cuarta Transformación. A través de este conflicto ecoterritorial, que ha despertado la oposición de movimientos sociales e indígenas, se plasmará este choque de visiones y se corroborará el avance de las fronteras extractivas gracias, entre otros aspectos, a la vulneración de derechos humanos como el derecho a consulta del Convenio I69 de la OIT. Por último, el artículo invitará a mirar el Tren Maya desde una mirada de las cartografías críticas, que lo interrelacionarán con proyectos mayores y que revelarán México como un país laboratorio de los tratados de comercio internacional que han propiciado la expansión de megaproyectos en el país.

* Laura CASANOVA CASAÑAS,

Graduada en Periodismo por la Universidad Pompeu Fabra, Máster en Periodismo Político Internacional por IDEC-UPF y Postgrado en Cultura de Paz por la Escola de Cultura de Pau de la Universidad Autónoma de Barcelona.

Recibido: 15/09/2020

Aceptado: 21/12/2020

\section{Palabras clave}

Conflictos ecoterritoriales; Extractivismo; Derecho a consulta; México; Tren Maya.

\section{Title}

Megaprojects and ecoterritorial conflicts. The case of the Mayan Train

\section{Extended Abstract}

Capitalism has imposed a dynamic of multiple forms of violence in the Global South, particularly since the last decades of the 20th century, with the onset of neoliberalism and as the Washington Consensus settled. This package of measures promoted mainly by the Bretton Woods institutions, the International Monetary Fund and the World Bank, was a turning point in economic policies and led the way to the consolidation of the current context of neoliberal globalisation. This article takes this macroeconomic panorama as a starting point to analyse the current violence that keeps the Latin American peoples subordinated in what Johan Galtung identifies as "the conjunction between the cultural violence of the mainstream economic theory and the structural violence of the mainstream economic practice" (2003, p. 2 II).

Among these many forms of violence, perpetrated from an extractivist, Eurocentric, colonial and patriarchal point of view, this analysis will focus on the ones generated when accumulation by dispossession (Harvey,2005) practices are involved and how these transform indigenous territories in Latin America. It is in this context where the transnational corporations' practices of accumulation by dispossession, reflected in megaprojects, and the indigenous world-views clash. Adopting Rocío Silva's

DOI:

https://doi.org//0.15366/relacionesinternacionales202I.46.008

Formato de citación recomendado:

CASANOVA CASAÑAS, Laura (202I). “Megaproyectos y conflictos ecoterritoriales. El caso del Tren Maya”, Relaciones Internacionales, $n^{\circ} 46$, Pp. 139-159. 
concept, these are "ecoterritorial" conflicts: conflicts that arise from the use and management of territories, understanding territory as a holistic concept that covers the social, cultural, economic and spiritual relations that compose them (20I7).

In this sense, we aim to extract from the opposition of these two antagonistic world visions: on the one hand, the modernity paradigm, with an extractivist modus operandi based on the neoliberal discourse; and, on the other hand, the indigenous world-views, which fight on a daily basis to build different realities and forms of organisation. This approach takes into account perspectives like ecofeminism, which will shed light on the interdependence between territories and bodies as vulnerable spaces, and Jason W. Moore's world-ecology paradigm, which will allow reading megaprojects as yet another product of capitalism that systematically exploits human beings and nature at the service of accumulation.

The historical debate on the concept of development also adheres itself to this clash of world views. The objective is to present alternatives to the current mainstream model of development, which is based on a Western approach and works as a new form of colonialism. In opposition to "the ghost of development" (Quijano, 2000), alternative notions to the conventional discourse pose different realities to build, like the Buen Vivir and Vivir Bien proposals. These epistemologies of the South assert that developmentalism has reached its limits and alert of the devastating consequences of driving indigenous territories into the market economy as exploited subjects: exactly what megaprojects usually intend to do in these lands.

Against this background, ecoterritorial conflicts have become one of the main challenges for Latin America in the 2Ist century and, in them, it is possible to see the asymmetry between the actors engaged in struggle.This asymmetry is reflected, on the one hand, on transnational corporations' impunity and, on the other, in the criminalisation of the indigenous peoples' resistance.As Boaventura de Sousa Santos says, in the current neoliberal system,"the only option that doesn't exist is a way out of this market" (20I4, p. I7).

In front of what looks like a non-option, this article will approach those resistances woven from the social movements, from below, and it will do so by taking as an example the case of the MayanTrain:the flagship megaproject of the president of Mexico, Andrés Manuel López Obrador, for the southeast of the country. The aim is to highlight the promised false development that supposedly comes with this project within the framework of the so-called Fourth Transformation, which, in spite of the aura of its socially beneficial character, is perpetuating the neoliberal approach of former Mexican governments. The ecoterritorial conflict generated by the Mayan Train, which has aroused opposition from social and indigenous movements, will reflect the above-mentioned clash of visions and will demonstrate the advance of extractivist borders. This is due to, among other aspects, the violation of human rights like the right to consultation of the ILO Convention I69, which has constitutional status in Mexico. Opacity has characterised the Mayan Train's project from the beginning and it has sown the seeds of uncertainty before the indigenous communities. Mexico is obliged to consult them in accordance with international standards, although conditions have clearly have not brought this about.

Lastly, the text will try to expand the focus to see the Mayan Train together with other larger projects. From this viewpoint, this train would only be a part of the ambitious plan of the Mexican Government for the territorial reorganisation of the southeast of the country, which has not been industrialised like other areas of Mexico.This perspective will be implemented with the help of critical cartographies, which will interrelate the Mayan Train with projects like the Trans-Isthmian corridor, the Sembrando Vida programme, or the Special Economic Zones, among others. These megaprojects, which in addition to the profits that are generated for transnational corporations who are awarded them, and to the dispossession processes that communities will suffer, are going to define human mobility in the South border of Mexico as a buffer in-between for migrations directed to the United States. What is more, they will show Mexico as a laboratory country of the international trade agreements ratified by the Government of Mexico that have enabled the expansion of megaprojects in the country. Indeed, transnational corporations have found Mexico to be a paradise for expansion since 1980, when the State's role in economic activity started to diminish - especially since the beginning of the millennium when the presence of transnational companies started to increase-. An increase that reflects the need of capitalism for the relentless appropriation of borders "in order for the wheel of accumulation to keep spinning" (Molinero and Avallone, 20I6, p. 33).

\section{KEYWORDS}

Ecoterritorial conflicts; Extractivism; Right to consultation; Mexico; Mayan Train. 


\section{ntroducción}

Con el pleno despliegue del Consenso de Washington, las últimas décadas del siglo XX

establecieron las bases para la consolidación del actual contexto de globalización neoliberal. Este artículo parte de este escenario macroeconómico para analizar los procesos de acumulación a los que da amparo y que transforman de manera recurrente territorios indígenas en América Latina a través de múltiples violencias. De la oposición entre estos procesos de despojo y los alterdesarrollos planteados por los pueblos originarios nace un choque entre dos visiones antagónicas del mundo: el paradigma de la modernidad, con un modus operandi extractivista basado en un discurso neoliberal; y las cosmovisiones indígenas, que luchan por construir realidades y formas de organización distintas.

Es precisamente en este choque donde se producen conflictos. Se defiende hablar de conflictos ecoterritoriales, al considerar que las disputas "surgen del uso y la gestión de los territorios" (Silva, 2017, p. 14). Asimismo, este enfoque también toma en cuenta la perspectiva ecofeminista, señalando la interdependencia entre los territorios y los cuerpos como espacios vulnerables ante las acciones de empresas transnacionales (ETN), y aplica el paradigma de la ecología-mundo de Jason W. Moore, con el cual se mirarán los megaproyectos como otra estrategia del capitalismo global para ampliar las fronteras de producción y maximizar la acumulación.

El artículo ejemplificará el choque de visiones a través del caso delTren Maya:el megaproyecto estrella del presidente de México, Andrés Manuel López Obrador (AMLO), que promete un falso desarrollo para el sureste del país en el marco de la llamada Cuarta Transformación. Falso argumentalmente porque parte de una premisa falaz al asegurar que la obra traerá desarrollo al sureste del país basándose en un modelo extractivista que beneficia el interés privado, como veremos más adelante, por encima de las necesidades de los pueblos que habitan en el trayecto del tren. Tanto es así que la infraestructura ha despertado la oposición de movimientos sociales e indígenas, que han denunciado, entre otros aspectos, que no se ha posibilitado de manera adecuada el derecho a consulta previa, libre e informada.

Asimismo, el trabajo propondrá enmarcar la obra en proyectos mayores. Partiendo de esta visión, el Tren Maya sería solo una pieza del ambicioso plan de reordenamiento territorial del sureste mexicano, que no se ha industrializado como otras zonas del país. Se invitará, pues, a ver el proyecto desde una mirada de las cartografías críticas, que interrelacionarán el Tren Maya con proyectos como el Corredor Transístmico. Estos proyectos revelarán la ampliación de las fronteras extractivas y desnudarán una lógica en la que México se ha convertido en un país laboratorio de los tratados de comercio internacional, que han permitido la amplia expansión de megaproyectos en el país.

\section{Conflictos ecoterritoriales en América Latina}

Este artículo pone el foco en los conflictos relacionados con disputas por territorios, que dibujan actualmente una tendencia al alza en la mayor parte de países de América Latina como reflejo de las múltiples crisis que existen consecuencia del sistema capitalista. Siguiendo la propuesta de Rocío Silva Santiesteban (2017), nos encontramos frente a conflictos ecoterritoriales, más que conflictos socioambientales. Silva une en este concepto dos ideas: por un lado, el concepto de giro 
ecoterritorial de Maristella Svampa, que recoge la tendencia de las narrativas indigenistas de unirse con el discurso ambiental y autonómico y de los feminismos populares (Svampa, 2019, p. 96); y, por el otro, la reflexión de Raphael Hoetmer, que considera que socioambiental es un "eufemismo que esconde uno de los más antiguos enfrentamientos humanos: por el uso y posesión de los territorios" (Silva, 2017, p. 16).

La noción de territorio se presenta como concepto holístico que abarca tanto las geografías físicas como el conjunto de relaciones sociales, culturales, económicas y espirituales que se dan en ellos. Por ello, es imprescindible tomar en consideración los aportes del ecofeminismo, que señalan las equivalencias e interdependencias existentes entre territorio y cuerpo: los cuerpos son finitos, como la Tierra; los cuerpos son vulnerables, como la naturaleza; los cuerpos son espacios de disputa, como los territorios. Son, a la vez, dos conceptos íntimamente ligados a las condiciones para la reproducción de la vida. Así, tanto el cuerpo como el territorio aparecen como sujetos donde el sistema capitalista pretende imponer sus reglas.

A su vez, incluimos el paradigma de Jason W. Moore, la ecología-mundo, que señala, como el ecofeminismo, el vínculo entre el bienestar de los cuerpos y el medioambiente, y critica el dualismo cartesiano del pensamiento europeo (Moore, 2016, p. 146). El autor defiende que la estrategia civilizatoria del capitalismo ha construido "la naturaleza como algo externo a la actividad humana" para así "movilizar el trabajo no mercantilizado de la naturaleza, humana y extrahumana, con el objetivo de aumentar la productividad de la producción de mercancías" (Moore, 2016, p. 144). Al dibujar la naturaleza fuera de la civilización, el capitalismo asienta una "falacia diseñada con el objetivo de permitir el ejercicio del poder indispensable para el proceso de acumulación" y "estructura una racionalidad según la cual ésta es directamente apropiable para la producción" (Molinero y Avallone, 2020, p. 31).

\section{I.I Choque de visiones}

Los conflictos ecoterritoriales nos devuelven una imagen de dos visiones del mundo antagónicas. En un extremo, encontramos el paradigma de la modernidad, expresado en el modus operandi de las ETN en los territorios indígenas, en un escenario de expansión del capital y procesos de acumulación; en el otro, las cosmovisiones de los pueblos indígenas, en las cuales hay un fuerte vínculo con el territorio como comunidad de vida. En este sentido, Svampa subraya el hecho de que la narrativa de las grandes corporaciones y los gobiernos "suele desplegar una concepción binaria del territorio", que deriva en dos nociones: la de "territorio eficiente" y la de "territorio vaciable" o, incluso, "sacrificable" (2008, p. 8). Se trata de un discurso que justifica el reordenamiento territorial.

Estas nociones de territorio se pueden trasladar a los debates académicos sobre el concepto de vida prescindible: desde el concepto de residuos humanos de Zygmunt Bauman, con el que se refiere a aquella población a quien la modernidad deja morir para asegurar la vida de otros seres humanos (2005, p. 16), hasta el concepto de necropolítica de Achile Mbembe, entendida como la regulación de poblaciones a través de la producción de sujetos disponibles y desechables a raíz de lo que necesita el régimen de acumulación (Fuentes, 2012, p. 7). También Raúl Zibechi se refiere, recuperando a Frantz Fanon, a las poblaciones que viven en las "zonas del no-ser" (2019). Estas 
visiones se complementan con la ecología-mundo, que describe el capitalismo como "un sistemamundo que coproduce la naturaleza (tanto humana como extrahumana) poniéndola al servicio de la acumulación” (Molinero y Avallone, 2020, p. 32).

En este choque también identificamos el histórico debate acerca del concepto del desarrollo. Eduardo Gudynas analiza una serie de factores que sustentan y justifican el extractivismo como práctica aceptable para avanzar en el desarrollo nacional. En los discursos que unen la urgencia de progresar a la expansión de las fronteras extractivistas, el autor advierte del uso de la "flexibilización de las exigencias sociales y ambientales; el énfasis en beneficios sociales y ocultamiento o minimización de los impactos; el reduccionismo económico y mercantilización de la Naturaleza; la ampliación de las compensaciones económicas; las defensas políticas y una reformulación democrática que acota derechos y participación" (2014, p. 137). Son discursos adscritos al marco capitalista dominante: tal como apunta Moore, "el capitalismo no solo tiene fronteras; sino que está definido, fundamentalmente, por el movimiento de las mismas" (2016, p. 163). Se trata de una noción de desarrollo basada en un modelo occidental como una nueva forma de colonización vehiculada a través del contexto neoliberal y la globalización.

Ante este planteamiento, existen alternativas. América Latina es, de hecho, una de las regiones donde más voces críticas han surgido en contra del paradigma hegemónico del progreso desarrollista. "Hoy afloran otras concepciones marginadas del discurso y las prácticas convencionales, sobre todo originarias, propias de los pueblos y nacionalidades ancestrales del Abya Yala", celebra Alberto Acosta (2015, p. 30I). Son ejemplo de estas alternativas las ideas del Buen Vivir o Sumak Kawsay, en kichwa, o delVivir Bien o suma qamaña, en aymara. Estos planteamientos en construcción recuperan saberes, valores y prácticas "de la vida indígena comunitaria, que se centra en la armonía entre los individuos viviendo comunidad, entre los pueblos y de todos con la naturaleza" (Acosta, 20I5, p. 299).

En contraposición a lo que Aníbal Quijano denomina “el fantasma del desarrollo” (2000), el Buen Vivir y el Vivir Bien parten del hecho de que el desarrollismo ha llegado a sus límites, como demuestran la emergencia climática o los efectos devastadores de la inserción de los territorios indígenas en la economía de mercado como sujetos explotados. En este sentido, Fernando Huanacuni Mamani afirma que el Vivir Bien no se puede equiparar al desarrollo occidentalmente entendido, que califica como "altamente peligroso" si se aplica en sociedades indígenas. Huanacuni advierte que "la introducción del desarrollo entre los pueblos indígenas aniquila lentamente nuestra filosofía propia del Vivir Bien, porque desintegra la vida comunal y cultural de nuestras comunidades, al liquidar las bases tanto de la subsistencia como de nuestras capacidades y conocimientos para satisfacer nosotros mismos nuestras necesidades" (2010, p. 30).

Las Epistemologías del Sur (De Sousa Santos y Meneses, 20I4) se cuestionan "las raíces etnocéntricas, capitalistas, coloniales y patriarcales de este modelo, así como su perspectiva universal y homogeneizadora que invisibiliza las diferencias y otras concepciones de bienestar" (Echart y Villarreal, 2018, p. 144). Una idea que también sostiene Yayo Herrero al alertar que "el dualismo occidental que fractura la cultura de la naturaleza y los cuerpos", que crea seres privilegiados que viven como si no hubiera límites, "ha hecho que la política y la economía se organicen como si esos seres privilegiados fuesen el sujeto universal. El problema es que esa 
fantasía sólo puede mantenerse porque en espacios invisibles y subyugados, otras personas y otros territorios se ocupan, de forma no libre, de reproducir la existencia” (2019, p. 5).

En esta forma de colonización de la que habla Herrero se construye una pronunciada asimetría entre los actores en pugna, principalmente entre las ETN y los pueblos indígenas. Hay que recordar que, en los últimos años, las grandes corporaciones han adquirido cada vez más poder, habiendo gozado de un marco jurídico favorecedor. En este sentido, Molinero y Avallone describen cómo las ETN "han sostenido directamente la reproducción de las relaciones socioecológicas capitalistas, organizando ambas naturalezas [la humana y la extrahumana] con el fin de garantizar de forma gratuita o barata la obtención de los principales factores de producción" (2020, p. 36).

En cambio, la disidencia ante estos megaproyectos se ve a menudo amenazada. De hecho, América Latina se ha convertido en la región más peligrosa para defender los derechos humanos. De los 304 defensores y defensoras que fueron asesinados en 2019 en todo el mundo, según Front Line Defenders (2019, p. 4), 208 homicidios tuvieron lugar en América Latina y el Caribe, convirtiéndose en la región más mortífera para estas personas.

\section{El auge de los megaproyectos en México}

Para que los conflictos ecoterritoriales ocurran, hay que tener en cuenta cómo se insieren en el contexto económico globalizado. En las últimas décadas, México ha firmado hasta 13 tratados de libre comercio con 50 países. Destaca el Tratado de Libre Comercio de América del Norte (TLCAN), que firmó en 1994 con Estados Unidos y Canadá y que Mónica Vargas define como “el tratado de libre comercio más agresivo del mundo" (2020). Recientemente, este tratado ha sido sustituido por el Tratado México, Estados Unidos, Canadá (TMEC), que México ratificó en 2019, y también se ha concluido, en plena crisis del coronavirus, la modernización del Tratado de Libre Comercio UE-México.

El caso delTLCAN es paradigmático, pues ha sido fuente de fuertes resistencias. Entre estas luchas, destaca la que surgió el I de enero de 1994, fecha en que entró en vigor el acuerdo, cuando se produjo el levantamiento del Ejército Zapatista de Liberación Nacional (EZLN) oponiéndose al proyecto de marginación al que eran relegados los pueblos indígenas en el marco de la globalización neoliberal. Hoy, veintiséis años después, persisten profundos impactos generados por el TLCAN' en materia de derechos humanos. Así lo corroboró, en diciembre de 2019, la caravana de observación internacional \#ToxiTourMéxico, que recorrió los corredores industriales de México que han atraído, gracias a estos tratados, capital principalmente estadounidense y europeo:

\section{"Entendemos este proceso destructivo como el resultado de la irresponsable aplicación en México de condiciones}

\footnotetext{
Según una sentencia del Tribunal Permanente de los Pueblos (TPP) sobre libre comercio, violencia, impunidad y derechos de los pueblos en México (20I I-20I4), "el TLCAN forma parte de este entramado jurídico-político de dominación. No hay cruce de caminos entre los derechos humanos y los derechos corporativos; hay una profunda ruptura de la jerarquía y de la pirámide normativa del sistema de protección de los derechos humanos". El texto también señala como "crucial" comprender que elTLCAN no está diseñado para promover el bien social. Además, califica el tratado de "tremendamente violento" al regular la impunidad transnacional.
} 
desventajosas de los tratados de libre comercio firmados por nuestro país, que fomentaron en las empresas trasnacionales la práctica inmoral de la exportación de riesgos a través de la vigencia de un doble estándar, es decir, del no apego en nuestro país a normas sociales y ambientales que en sus países de origen sí han respetado o respetarían.” (Caravana Toxitour México, 2020, p. 4).

Este doble estándar se refleja en la creación de lo que el informe califica como paraísos industriales, como zonas de nula responsabilidad social y ambiental para las ETN, o bien como zonas sacrificables. Son ejemplos de cómo, especialmente a partir del TLCAN, México se ha convertido en un país laboratorio ${ }^{2}$ de la globalización neoliberal. En este sentido, las ETN han encontrado en México un paraíso donde expandirse desde 1980, cuando empezó a disminuir el rol del estado en la vida económica, y especialmente desde el principio del milenio, a partir del cual ha aumentado la presencia de ETN. Un crecimiento que se puede observar en su relación directa con en el aumento de la Inversión Extranjera Directa (IED) en el país: mientras que en I 980 la entrada neta de capital extranjero era de 2,09 mil millones de dólares, en 2019 la IED alcanzó los 29,36 mil millones (Banco Mundial, 2019). Según la CEPAL, México es el segundo mayor receptor de IED de América Latina y el Caribe (2020, p. 7I). Una situación que refleja la necesidad del capitalismo de apropiarse incesantemente de las fronteras "para que la rueda de la acumulación vuelva a girar" (Molinero y Avallone, 2016, p. 33).

\section{El caso delTren Maya}

Andrés Manuel López Obrador empezó su mandato el I de diciembre de 2018 en medio de este complejo contexto. Ya desde el Palacio Nacional, prometió impulsar la llamada "Cuarta Transformación”. El nombre no es baladí: con la Cuarta Transformación, entendida como un profundo cambio en la vida económica, política, social y cultural del país, el presidente quiere sumar un punto de inflexión más a los tres otros momentos decisivos de la historia de México: la independencia, la reforma y la revolución mexicana.

La Cuarta Transformación permite diseccionar la mirada de López Obrador respecto el desarrollo del país, que, en este sentido, da continuidad al modelo neoliberal de sus predecesores, a pesar de los esfuerzos de su gobierno de contraponerse a ellos y de construir una narrativa acorde. Así lo refleja la proyección, bajo su presidencia, de megaproyectos como el Tren Maya, el Programa para el Desarrollo del Istmo de Tehuantepec o el Corredor Transístmico, que se suman al programa Sembrando Vida, a la refinería de Dos Bocas y al ambicioso Proyecto de Integración y Desarrollo de Mesoamérica (antes llamado Plan Puebla Panamá). Todos son proyectos que han despertado oposición por sus impactos ambientales y sociales y por la falta de adecuación de las consultas previas a las poblaciones afectadas.

Pero centrémonos en la obra insignia del mandato de AMLO: el Tren Maya. El Plan de Desarrollo 2019-2024 del Gobierno de México lo describe como "el más importante proyecto

Referencia realizada por Mónica Vargas en la sesión “Recursos naturales, multinacionales y derechos humanos" del Postgrado de Cultura de Paz de la UAB. 30 de enero de 2020 
de infraestructura, desarrollo socioeconómico y turismo del presente sexenio" (Diario Oficial de la Federación, 2019). Se trata de un tren con un recorrido de mil 460 quilómetros que conectará a una velocidad máxima de $160 \mathrm{~km} / \mathrm{h}$ los principales puntos turísticos de la Península del Yucatán, con diecinueve estaciones y con un costo total de entre 5.500 y 7.000 millones de euros, y que transportará tanto turistas como mercancías. Casi la mitad del trayecto ya cuenta con vía férrea; el resto requiere de nuevas vías.

Sobre el papel, la obra ha de estar lista en 2023 para traer el "desarrollo" al sureste mexicano, una de las zonas más pobres y menos industrializadas de México. En este sentido, la ubicación del tren encaja con lo que Emiliano Teran describe al analizar cómo ha tenido lugar una "gran expansión de las fronteras extractivas" en América Latina, "avanzando en muchas ocasiones sobre territorios 'vírgenes', o que habían sido muy poco impactados por la modernización capitalista” (20I4). Es lo que advertía Moore con perspectiva histórica: "La extensión del poder capitalista a nuevos espacios no mercantilizados se convirtió en la savia del capitalismo" (2016, p. 147).

El tren impactará en la región sur mexicana no solo por la construcción de vías y estaciones, sino por el desarrollo asociado a él en cuanto a carreteras, construcción de hoteles y centros comerciales para el turismo de masas o los nuevos polos desarrollo urbano. Ante estas perspectivas, las dudas envuelven el proyecto: desde su impacto ambiental —la Manifestación de Impacto Ambiental (MIA) presentada por el Gobierno no abarca todos los impactos negativos al medio ambiente por el paso del tren, que atraviesa corredores biológicos en una región donde abundan las áreas protegidas - , pasando por su impacto arqueológico —el megaproyecto se dibuja sobre una zona de vestigios de la civilización maya, de la cual todavía no se conocen todos los sitios arqueológicos-, hasta su impacto social y económico sobre las comunidades involucradas en el trayecto. Asimismo, una preocupación reiterada es la poca información disponible y la falta de transparencia entorno a los detalles de la obra. 


\section{Trayecto del Tren Maya y estaciones previstas}



Fuente: Gobierno de México

A pesar del rechazo de comunidades indígenas y quejas de ambientalistas, los concursos para la construcción del Tren Maya ya se están adjudicando, con gran interés por parte de ETN. Según un informe del Proyecto sobre Organización, Desarrollo, Educación e Investigación (PODER), "las principales empresas involucradas en el proyecto son de capital español, chino y estadounidense, varias de ellas involucradas en actos de corrupción en México y Latinoamérica" (Clavijo y Castrejón, 2020, p. 39).Algunos ejemplos son CICSA, vinculada a uno de los empresarios más ricos del mundo según Forbes, el mexicano Carlos Slim (Forbes, 2020) que, en convenio con la española FCC, ganaron la construcción del tramo 2 de Escárcega a Calkiní; o el consorcio entre la portuguesa Mota-Engil y China Communication Construction Company (CCCC), que se llevó el primer tramo ferroviario del Tren Maya.

Considerando que se espera que el $70 \%$ de los ingresos generados por el Tren Maya provengan del transporte de carga, y que, de éstos, un $26 \%$ procedan de la carga de combustibles (Tabla I), PODER subraya la relación de la infraestructura con proyectos de generación de energía en la región que podrían beneficiarse, en los que destaca la participación del fondo de inversión 
estadounidense BlackRock ${ }^{3}$.Al analizar quiénes son los principales beneficiados del megaproyecto, pues, aparecen grandes élites económicas tanto mexicanas como internacionales que se están viendo claramente favorecidas por la construcción de esta megainfraestructura, frente a las muchas dudas sobre los beneficios del tren para las comunidades afectadas por su paso. Así lo concluye la investigación de PODER, que afirma que el Tren Maya es "un eslabón que permitirá la profundización del modelo extractivista de desarrollo" en el sureste de México (2020, p. 39).

Tabla I: Ingresos estimados del Tren Maya

\begin{tabular}{|c|l|l|l|}
\hline Concepto & Ingresos por & $\begin{array}{l}\text { Monto anual (en pesos } \\
\text { mexicanos) }\end{array}$ & Porcentaje \\
\hline \multirow{2}{*}{ Carga } & Alimentos & $15 \mathrm{mil} \mathrm{mdp}$ & $33 \%$ \\
\cline { 2 - 4 } & Combustibles & $12 \mathrm{mil} \mathrm{mdp}$ & $26 \%$ \\
\cline { 2 - 4 } & $\begin{array}{l}\text { Industria de la } \\
\text { construcción }\end{array}$ & $5 \mathrm{mil} \mathrm{mdp}$ & $11 \%$ \\
\hline Turismo & $\begin{array}{l}\text { Movimiento de } \\
\text { pasajeros }\end{array}$ & $14 \mathrm{mdp}$ & $30 \%$ \\
\hline Total & Ingresos estimados & $46 \mathrm{mil} \mathrm{mdp}$ & $100 \%$ \\
\hline
\end{tabular}

Fuente: Elaboración propia a partir de la Ficha Técnica del Tren Maya (Cámara de Diputados, 2019, p. 13).

En este sentido, una mirada a los planes de desarrollo asociado al Tren Maya muestra, de nuevo, un concepto de desarrollo neoliberal que choca con las cosmovisiones de los pueblos indígenas, muy presentes en el trazo del tren. Un estudio de Daniel Sandoval (2020, p. 6) concluye que habría mil 510 comunidades indígenas de los pueblos maya tzeltal, ch'ol, jakalteko, awuakateko y akateko, así como 533 ejidos. Dicho choque se puede identificar, entre otros, en la visión de la tierra por parte de estos pueblos. Señalando el condicionamiento cultural de los autores occidentales, Carlos Montemayor contrapone la visión de aquel que pertenece a la tradición judeocristiana, para quien "el mundo está al servicio nuestro", con la de pueblos indígenas, para quien "la tierra está viva, es un ser vivo, y de esa condición se derivan muchos compromisos para el hombre, que está al servicio del mundo” (2000, p. 98).

Consultar el informe de PODER para conocer más detalles de las empresas beneficiadas del Tren Maya: https://trenmaya.poderlatam.org/\#/ informeTM 


\section{Comunidades indígenas en el área de influencia del Tren Maya}

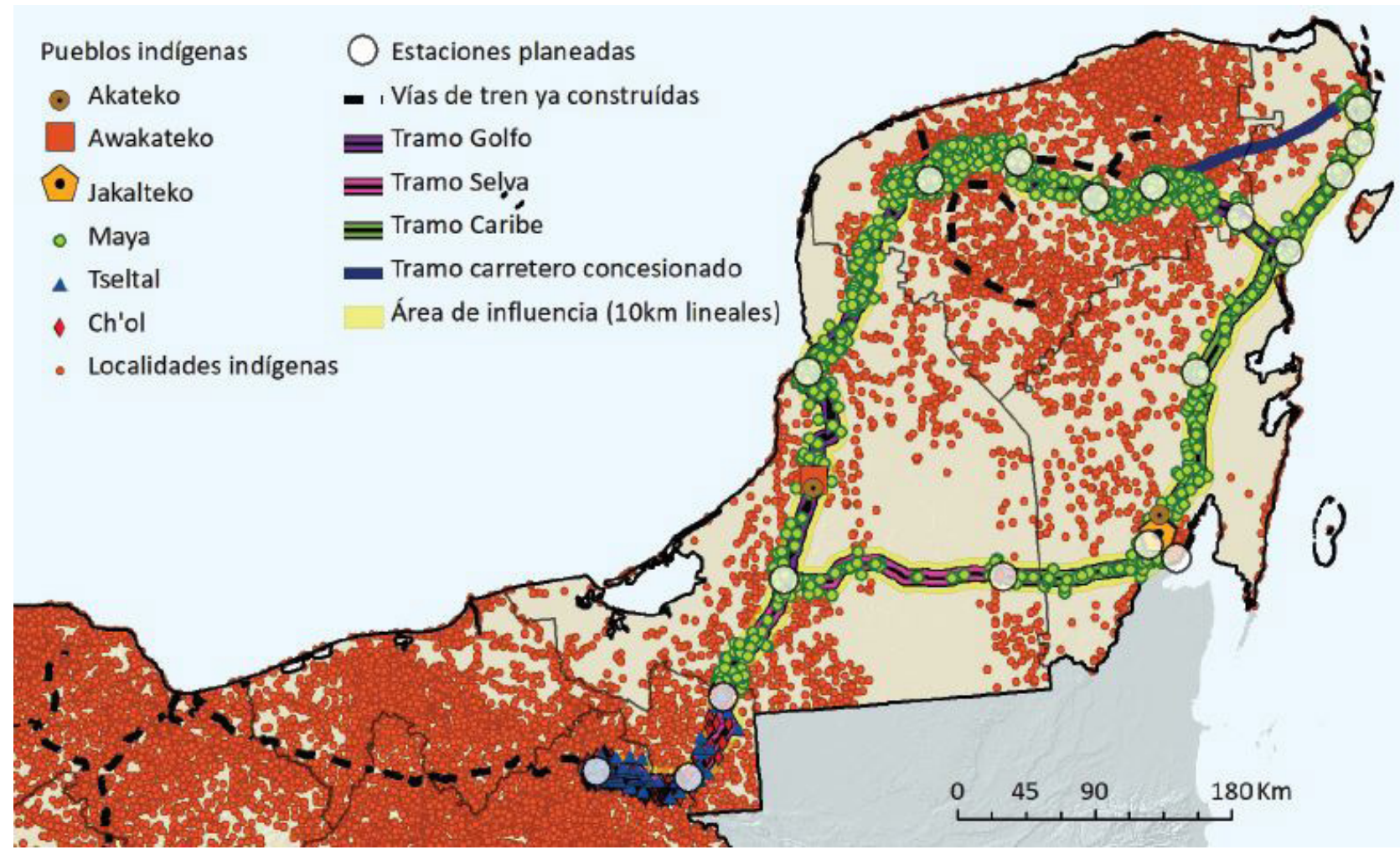

Fuente: SANDOVAL, Daniel, Tren Maya, Sembrando Vida y Corredor Transístmico. Impactos en el valor de uso territorial de las comunidades indígenas y campesinas. Centro de Estudios para el Cambio en el Campo Mexicano, México, 2020

A la idiosincrasia de la demografía del sureste mexicano hay que añadirle cuestiones de propiedad de la tierra. En México existen los ejidos y las comunidades agrarias, que se institucionalizaron después de la revolución mexicana y que no solo implican un tipo de propiedad social, sino también un modo de vida. Estas propiedades abundan en el recorrido planificado y, ante esta realidad, para la construcción de las vías el Gobierno de México se ha visto obligado a negociar con los ejidatarios. Para hacerlo, el ejecutivo les plantea que sean "socios" del proyecto, en vez de vender o expropiar sus tierras, a través de un Fideicomiso de Infraestructuras y Bienes Raíces (FIBRA), un instrumento financiero que cotiza en los mercados de capital para financiar proyectos inmobiliarios. Es importante notar que, aunque mediante las FIBRAS la tierra no se vende, sí que "es entregada como soporte material y financiero" (GC-TTM, 20 I9, p. I5). 


\section{Propiedad ejidal a lo largo del recorrido del Tren Maya}

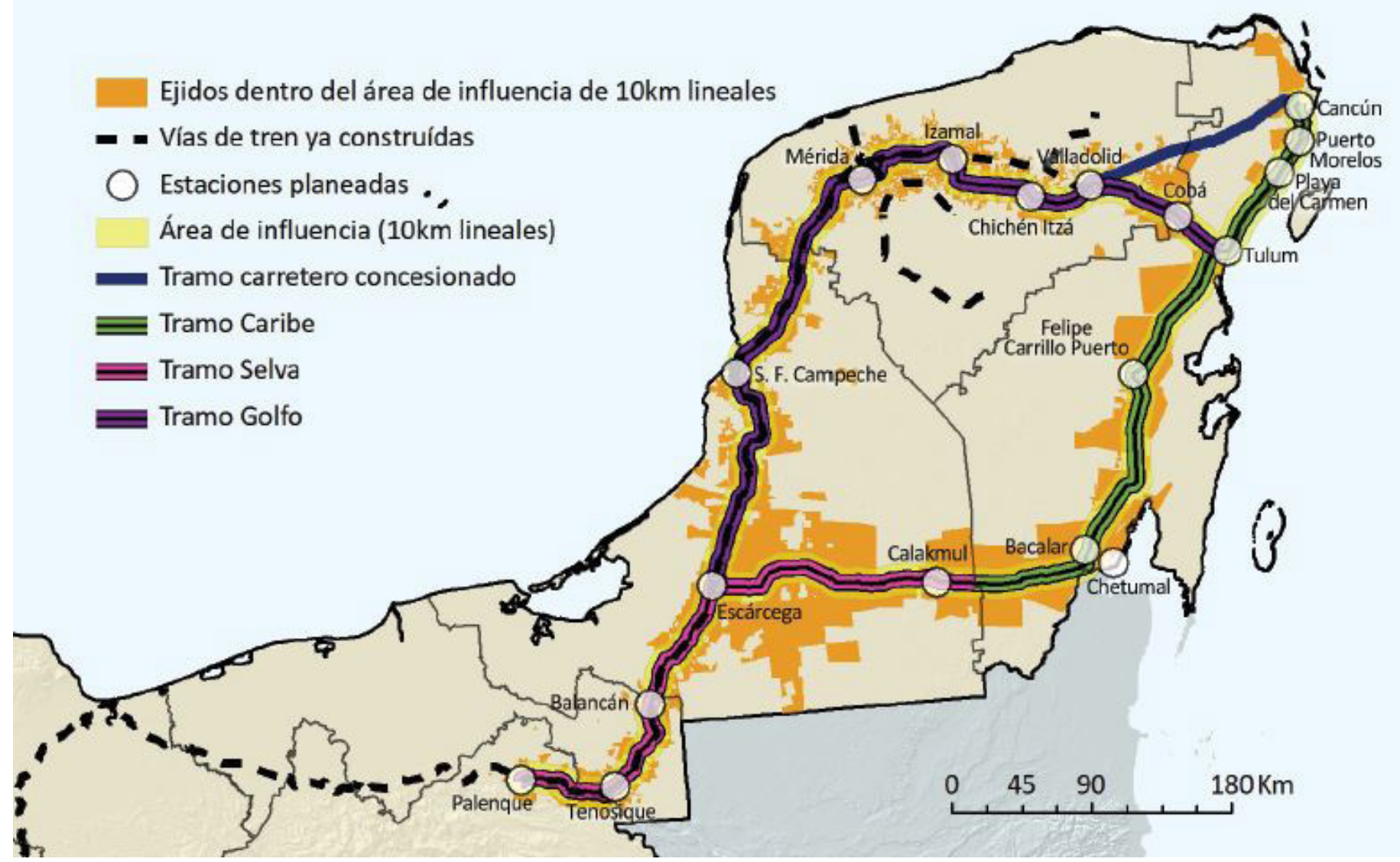

Fuente: SANDOVAL, Daniel, Tren Maya, Sembrando Vida y Corredor Transístmico. Impactos en el valor de uso territorial de las comunidades indígenas y campesinas. Centro de Estudios para el Cambio en el Campo Mexicano, México, 2020

Hay que tener en cuenta que sobre esa tierra "se construirán hoteles, condominios, parques industriales o cualquier otra edificación prevista en el Tren Maya, que no pertenece al dueño de la tierra sino a los socios o accionistas entre los cuales él podría tener una participación" (GC-TTM, 2019 , p. I5). En este sentido, Violeta R. Núñez advierte que "una vez que la tierra se ha otorgado al fideicomiso no hay retorno" (2020, p. II). Para Núñez, la propuesta de las FIBRAS podría implicar un proceso de despojo porque "además de que los ejidatarios nunca podrán recuperar su tierra (si lo quisieran) porque sobre ella estarán los proyectos inmobiliarios [...], tampoco tienen garantizada la rentabilidad, por lo que quizá en un futuro no les quedaría más opción que vender las acciones (certificados bursátiles) que reciban por sus tierras” (Núñez, 2020, p. II).

\section{I. El derecho a consulta en el megaproyecto del Tren Maya}

Como se ha señalado, en el recorrido del tren hay más de mil quinientas comunidades indígenas. El Gobierno de México ha insistido en vender el carácter sustentable y socialmente necesario del proyecto para estas poblaciones. Pero ¿qué dicen las comunidades locales afectadas? ¿Cómo se les ha consultado? 
El Derecho a la Consulta y al Consentimiento Previo, Libre e Informado (DCCPLI) está protegido por instrumentos jurídicos tanto nacionales como internacionales. Por un lado, las normas internacionales de más relevancia en este ámbito son el Convenio sobre pueblos indígenas y tribales (número 169) de la Organización Internacional del Trabajo (OIT) y la Declaración de las Naciones Unidas sobre los Derechos de los Pueblos Indígenas. Por el otro, a nivel nacional, en México el Convenio 169 entró en vigor en 1990 y goza de rango constitucional en el artículo segundo, relativo a los pueblos indígenas, y en el primero, que incorpora el derecho internacional a la Constitución y, por lo tanto, este instrumento de la OIT.Aun así, persisten muchas omisiones del derecho a consulta. En este sentido, Rodrigo Gutiérrez y Edmundo del Pozo concluyen que en México "el marco legal local en materia del DCCPLI (...) es en general muy deficiente y está alejado de los parámetros internacionales" (2019, p. 31).

En el caso del Tren Maya, el derecho a consulta también se ha visto diezmado, en línea con el olvido histórico que han sufrido las comunidades indígenas y la falta de respeto a sus derechos. Ya desde su campaña presidencial, AMLO aseguró que el proyecto se sometería a consulta en los territorios involucrados por el paso del tren. En noviembre de 2019, el presidente firmó la convocatoria con la cual se daba inicio al proceso de consultas para determinar su construcción. En este proceso calificado como histórico, y según la información oficial, las comunidades que asistieron a las asambleas regionales consultivas en los cinco estados implicados en el Tren Maya - Chiapas, Tabasco, Campeche, Yucatán y Quintana Roo- aceptaron por consenso la implementación del megaproyecto. En el cuadro siguiente se presentan las cifras oficiales por etapas: 


\section{Tabla 2: Proyecto de Desarrollo Tren Maya}

\section{Actos previos}

Se configuran I 5 regiones indígenas donde se llevarán a cabo las asambleas regionales. En esta etapa también se realiza el protocolo y la convocatoria de consulta.

Etapa informativa

Se entrega la información disponible del proyecto en I 5 asambleas regionales informativas durante los días 29 y 30 de noviembre de 2019.

\begin{tabular}{|l|l|}
\hline Asistentes & $\mathbf{4 . 8 6 9}$ personas \\
\hline & $\mathrm{I} .863$ como autoridades comunitarias, municipales y agrarias \\
\cline { 2 - 2 } & de 1.078 comunidades indígenas de las 1.440 convocadas $(74,86 \%)$ \\
\hline
\end{tabular}

Etapa deliberativa

Las comunidades indígenas, con la información de la que disponen, deliberan sobre el proyecto. Etapa consultiva

Entre el 14 y el I 5 de diciembre se dialoga con las comunidades indígenas en 15 asambleas regionales consultivas sobre las propuestas y opiniones planteadas para llegar a acuerdos.

\begin{tabular}{|l|l|}
\hline Asistentes & $\mathbf{5 . 4 3 6}$ personas \\
\hline & $\mathrm{I} .639$ como autoridades comunitarias, municipales y agrarias \\
\cline { 2 - 2 } & de 985 comunidades indígenas de las 1.440 convocadas $(68,4 \%)$ \\
\hline
\end{tabular}

Etapa de seguimiento

Se designa una Comisión de Seguimiento y Verificación para el debido cumplimiento de los acuerdos con 293 integrantes (226 hombres y 67 mujeres).

Fuente: Elaboración propia a partir de la presentación de resultados del Gobierno de México ( 23 de diciembre de 2019).

A pesar de que el ejecutivo presume de haber puesto en manos de los pueblos la decisión de acuerdo con los estándares internacionales, pocos días después de la etapa consultiva, el 19 de diciembre de 2019, la Oficina en México del Alto Comisionado de las Naciones Unidas para los Derechos Humanos (ACNUDH México) apuntaba que el proceso no había cumplido con todos los compromisos que México tiene en la materia,y detallaba deficiencias en las consultas. El informe lamentaba que la información presentada en el proceso mencionaba solo los beneficios del proyecto, y no los posibles impactos negativos; observó que en alguna sesión las personas de las comunidades expresaban su conformidad como medio para recibir atención con respecto a necesidades básicas; $y$ criticó la decisión unilateral de las autoridades en la definición de a quién consultar, dónde y cuándo ${ }^{4}$. El gobierno de AMLO rechazó estas observaciones ${ }^{5}$.

A su vez, el Centro de Derechos Humanos Fray Bartolomé de las Casas (Frayba) definió las consultas como "simuladas" y aseguró que daban continuidad a "políticas de no reconocimiento

\footnotetext{
La organización asistió como observadora del proceso de consultas a instancias del Gobierno de México.

En un comunicado de prensa el 23 de diciembre de 2019, el Gobierno de México expresó su preocupación ante las descalificaciones de ACNUDH México, "pues prejuzgando sobre hechos futuros relacionados con el proyecto de desarrollo, abonan a un clima de incertidumbre y de falta de respeto a la legítima voluntad que han expresado las comunidades indígenas” (Gobierno de México, 20I9).
} 
de los pueblos originarios como sujetos de derechos" (2020). Para este centro, proyectos como el Tren Maya subordinan a los pueblos originarios "a integrarse a un programa previamente ya decidido y se les mira como objeto de explotación” (ibidem).

Las irregularidades expuestas muestran brechas en la manera como se implementó el proceso de consulta. De hecho, la consulta ha llegado a los tribunales, que en marzo de 2020 ordenaron la suspensión definitiva de la ejecución del megaproyecto en el tramo de Bacalar a Escárcega tras aprobarse un recurso de amparo del Consejo Regional Indígena y Popular de Xpujil. La solicitud denunciaba la "ilegal consulta y aprobación del proyecto denominado Tren Maya, cuya acción se realizó en flagrante violación a nuestro derecho humano a que se garantice una consulta previa, libre, informada, de buena fe y culturalmente adecuada" (Arellano y Briceño, 2020).

\subsection{Resistencias al Tren Maya}

Si bien la oposición al megaproyecto ya está dando resultados, como demuestra esta decisión judicial, éste no es el único frente de resistencia. Los movimientos sociales plantan cara activamente a los megaproyectos, ya sea a través de acciones colectivas, protestas, marchas o campañas de sensibilización, así como elaborando informes alternativos o, como hemos visto, usando las vías legales. Las luchas de las comunidades no sólo alzan la voz contra conflictos concretos, sino que hacen una enmienda a la totalidad al modelo de desarrollo impuesto, reflejando, de nuevo, el choque de visiones planteado.

Desde el inicio de la presidencia de AMLO, el Congreso Nacional Indígena (CNI) o en el EZLN, entre otros, reiteran su firme oposición "a las políticas neoliberales de los viejos y nuevos gobiernos", en referencia tanto al Tren Maya como a la Cuarta Transformación en conjunto, "y a las consultas, se llamen como se llamen, que no tienen otro fin que el despojo de nuestros territorios" (Enlace Zapatista, 2019). Asimismo, a mediados de 2020, 159 organizaciones y 85 activistas mandaron una carta a AMLO mostrando su rechazo al megaproyecto, poniendo sobre la mesa la violación del derecho a consulta, cuestionando la viabilidad medioambiental de la infraestructura y recordando los riesgos que supone al patrimonio histórico y cultural de la Península del Yucatán.

Para combatir la opacidad, la sociedad civil también ha dado voz a las comunidades para desnudar el "mal llamado" Tren Maya en foros virtuales. En una de estas conferencias ${ }^{6}$, Ángel Sulub, del Centro Comunitario U kúuchil k Ch'i’ibalo'on de Quintana Roo, puso de ejemplo el desarrollo de Cancún en la década de los setenta para evidenciar el modelo del que también nace el Tren Maya y en el que el gran capital ha visto "la posibilidad de continuar con el saqueo de nuestros territorios" (Red Universitaria Anticapitalista, 2020). En este sentido, Sulub aseguró que el Tren Maya, como otros megaproyectos, "no vienen para salvarnos de nada, sino todo lo contrario: no se acordaron de nosotros. Más bien se acordaron de las riquezas que protegemos y que protegen los pueblos indígenas del mundo" (Red Universitaria Anticapitalista, 2020). En el mismo foro, Pedro

6 Se trata de un foro organizado por la Red Universitaria Anticapitalista para abordar las consecuencias del megaproyecto bajo el título "Un tren contra los pueblos mayas". En la charla participan Carlos González, del Congreso Nacional Indígena; Pedro Uc, de la Asamblea de Defensores del Territorio Maya; Sara López González, del Consejo regional indígena y popular de Xpuji; y Ángel Sulub, del Centro Comunitario U kúuchil k Ch'i’ibalo'on. La intervención de Sulub es a partir del minuto 36 y la de Uc, a partir del $5 \mathrm{I}$. 
Uc, de la Asamblea de Defensores del Territorio Maya, recorría a la memoria de la colonización y al "desarrollo que trajeron los europeos" hace más de 500 años para recordar el origen de la marginación actual de los pueblos originarios en México. Hoy, con el Tren Maya, este modelo de desarrollo pervive.

\subsection{Una mirada desde las cartografías críticas}

Pervive,y se expande.EmilianoTeran avisa que,"si mapeáramos los diversos proyectos de explotación de la naturaleza en los países latinoamericanos, podríamos advertir con gran preocupación cómo cada vez más territorio es comprometido, hipotecado y/u ocupado por la lógica de despojo y depredación del capital" (20/4). En efecto, México cumple estas características, que se reflejan en cómo se vincula el Tren Maya a otros megaproyectos que se están acumulando en el sur y sureste del país. En este punto, las cartografías críticas resultan una herramienta ideal, ya que, contrapuestas al mapeo oficial,"resaltan la dimensión política de los territorios, siempre vinculada a la existencia de disputas de poder por el control sobre el espacio" (Basualdo, Domenech y Pérez, 2019, p. 45).

Las cartografías críticas nos invitan a ver el Tren Maya solo como la punta del iceberg y a ampliar el foco a todo el territorio mexicano e, incluso, al continente. Al hacerlo, aparece el Proyecto de Reordenamiento Territorial del Sur-Sureste, un "gran proyecto regional conformado por una multiplicidad de otras iniciativas (entre las que se encuentra el Tren Maya, Sembrando Vida, las Zonas Económicas Especiales (ZEE), y el Corredor Transístmico), hacia un objetivo de largo aliento y aún inconcluso: el control, reparto e instrumentalización neoliberal de territorios y pueblos de la península" (Flores, Deniau y Prieto, 2019, p. 12). Por otro lado, Sandoval coincide en alertar de la estrecha relación entre el Corredor Transístmico, el Tren Maya y el programa Sembrando Vida como "una triada diseñada para el despojo y la subordinación del territorio hacia un conjunto de usos que transforman y se oponen a las relaciones sociales comunitarias de los pueblos originarios" (2020, p. 37). 


\section{Relación entre los megaproyectos del Tren Maya, el Corredor Transístmico, las ZEE el Plan Frontera Sur y la Refinería de Dos Bocas con las principales rutas migratorias}

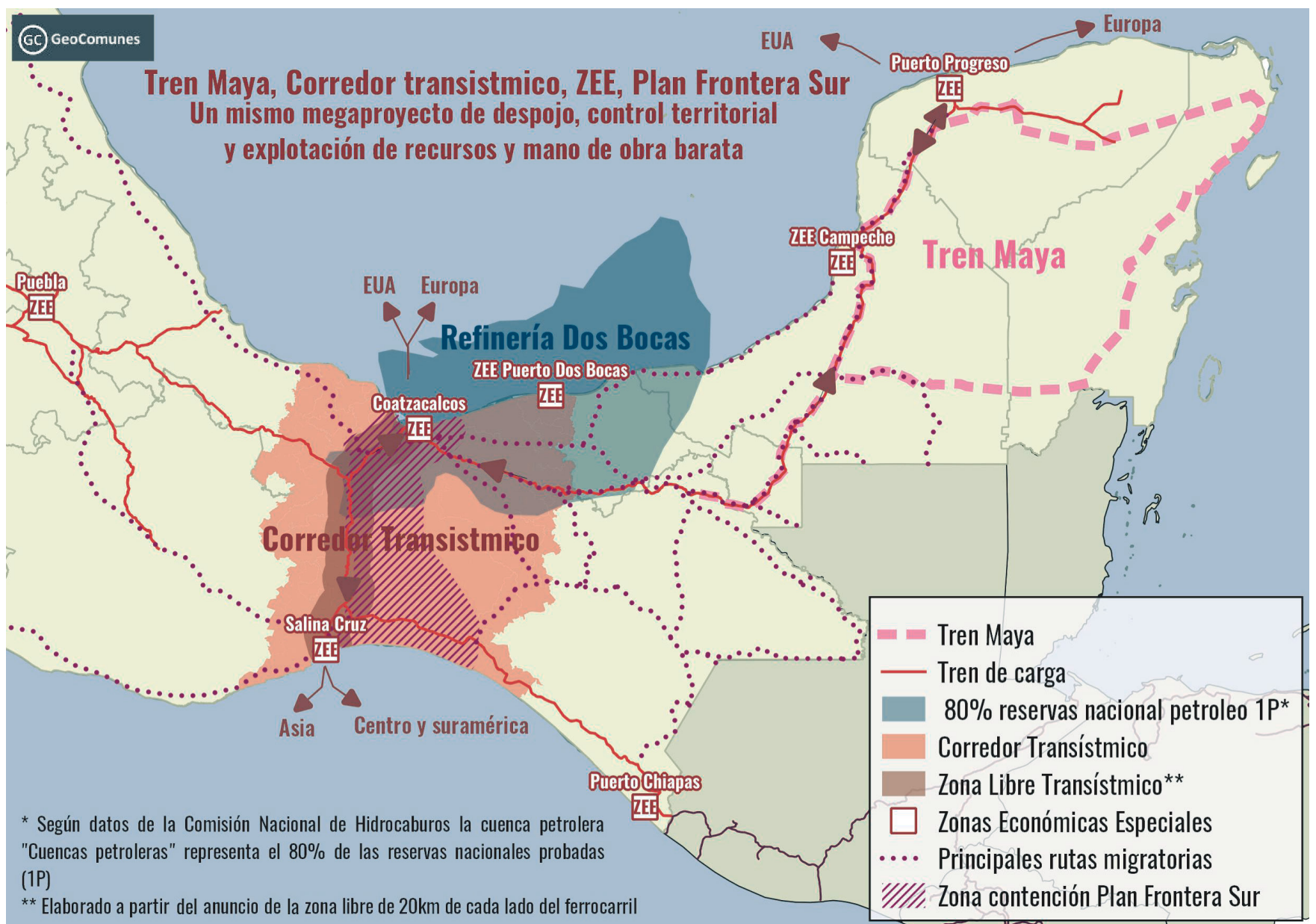

Fuente: GeoComunes

Más allá del territorio nacional, encontramos el Plan Puebla-Panamá, hoy Proyecto de Integración y Desarrollo de Mesoamérica, o Proyecto Mesoamérica. Un megaproyecto regional, que, a ojos de Jorge Luis Capdepont-Ballina, sería un mecanismo para convertir a los países de la región en exportadores de materias primas y compradores de manufacturas:"No hay programas de industrialización para dicha zona, sino para el establecimiento de maquilas, las cuales aprovecharán al máximo la biodiversidad en el área y la mano de obra no calificada” (2010, p. 165).

En relación a esta mano de obra, un estudio de GeoComunes y el Consejo Civil Mexicano para la Silvicultura Sostenible aborda las implicaciones del Tren Maya en la movilidad humana. Se menciona el Plan de Desarrollo Integral para Centroamérica, del que subrayan que "es un paso más en la consolidación de México como país tapón de las migraciones hacia Estados Unidos, y de la región Frontera Sur como territorio de amortiguamiento, contención e instrumentalización asociado" (Flores, Deniau y Prieto, 2019, p. 15). Asimismo, Salomé Cabrera y Sergio Prieto plantean que el Tren Maya "articulará las industrias y maquilas neoextractivas del sur de México y norte de Centroamérica hacia los mercados mundiales” y, junto con las ZEE, “serán un mercado 
de atracción de las migraciones regionales, y tendrán fuertes implicaciones en los procesos de movilidad interna de las comunidades, provocando dinámicas potencialmente conflictivas" (2019). Así se afirma también desde instancias oficiales: el Plan Nacional de Desarrollo 2019-2024 del Gobierno de México afirma, al referirse a cuestiones migratorias, que se espera que "los proyectos regionales de desarrollo actúen como 'cortinas' para captar el flujo migratorio en su tránsito hacia el norte” (Diario Oficial de la Federación, 2019).

Vista la interrelación de los proyectos, Prieto ve en la situación actual del sureste mexicano un espejo de las dinámicas mundiales, ya que "es una muestra relevante de problemáticas globales en las que los países históricamente dependientes siguen subordinados y sirviendo a los intereses geopolíticos de las grandes potencias hegemónicas (nacionales o mercantiles), así como de las estructuras multinacionales que las amparan” (2020, p. 20).

\section{Conclusiones}

A lo largo del artículo, se ha analizado lo que se ha planteado como un choque de visiones entre dos miradas antagónicas del mundo: el choque que se da entre las ETN y los pueblos originarios; entre la noción de territorio - y, por ende, de la población que lo habita- como espacio sacrificable, y la noción del mismo como comunidad de vida; la oposición que tiene lugar al contraponerse los megaproyectos de despojo y la lucha por la vida. La colisión, en definitiva, entre la óptica neoliberal y las cosmovisiones indígenas. Para evidenciarlo, se han analizado como reflejo de esta pugna los conflictos ecoterritoriales, que ponen el uso y la gestión del territorio en el centro del conflicto. A través de las miradas de distintos autores, así como voces de los pueblos y la sociedad civil, se ha desnudado el concepto de desarrollo que se vende desde instancias públicas y privadas para acercarse a los pocos territorios que se mantienen vírgenes del capitalismo desenfrenado, aquellos donde la vida aún se protege y se pone en el centro.

Poner la vida en el centro también implica cuestionar el paradigma hegemónico del progreso desarrollista y del capitalismo como sistema para despojarlo de legitimidad y exponer las entrañas de lo que es una única crisis, como advertía Moore: la de la ecología-mundo capitalista como forma de organizar la naturaleza y como proyecto civilizatorio (2016, p. 149). En este sentido, es imprescindible recalcar que este sistema genera múltiples violencias: desde la que amenaza y coarta a los pueblos, y la que mata a defensores de derechos humanos, hasta la que se refleja en el desprecio cultural que padecen los pueblos, en un neocolonialismo que permite la burla de que un megaproyecto de despojo lleve por nombre Tren Maya.

En esta lógica también se insiere la Cuarta Transformación de AMLO, que, a pesar de la narrativa que sustenta su carácter socialmente beneficioso, está dando continuidad a la mirada neoliberal de los anteriores gobiernos mexicanos. De esta manera, México continúa ejerciendo de país laboratorio de los acuerdos comerciales internacionales y sus políticas económicas, que abonan el terreno para el avance de los procesos de acumulación y el despliegue de megaproyectos en el país.

Este trabajo ha tomado como caso de estudio el Tren Maya, que, con la ayuda de las cartografías críticas, se ha desvelado no como un proyecto de reordenamiento territorial aislado, 
sino como una pieza más del puzle para abrir las puertas del sureste del país al gran capital. A la obra insignia del sexenio de AMLO se le suman el Corredor Transístmico, el programa Sembrando Vida, el Proyecto Mesoamérica o el Plan de Desarrollo Integral para Centroamérica, entre otros. Megaproyectos que, además del lucro que supondrán para las ETN que se los adjudiquen y del despojo que implicará en los pueblos, definirán la movilidad humana en la frontera sur de México como país tapón de las migraciones hacia Estados Unidos.

Mediante el análisis del Tren Maya también se ha abordado como clave el derecho a consulta para poner en el centro la voz de los pueblos indígenas afectados por el megaproyecto. Ante las deficiencias expuestas, concluimos que se trata de un derecho humano que se ha visto limitado en la determinación de esta megainfraestructura. La opacidad ha caracterizado el proyecto desde su inicio y ha sembrado un campo de incertidumbre que ha hecho que las comunidades involucradas no hayan sido consultadas de manera adecuada según los estándares internacionales. Solo se han podido anticipar a sus efectos.

Como alababa la sentencia del capítulo México del TPP en 20 I4, los movimientos sociales mexicanos llevan décadas cargando con el peso de poner palabras al silencio y al olvido de los crímenes que han tenido lugar en el país (20I4, p. 36), a la sombra de las dinámicas impuestas por los acuerdos comerciales internacionales que, lejos de promover el bien social, han expandido las fronteras extractivas y, con ellas, los conflictos ecoterritoriales. Como demuestra el caso del Tren Maya, a las resistencias de la sociedad civil les queda mucho camino por recorrer con esta pesada mochila en la espalda, que solo irán vaciando a medida que la asimetría entre empresas transnacionales y pueblos indígenas cambie de lado para proteger, por fin, la vida.

\section{Referencias}

Acosta, A. (20I5). El Buen Vivir como alternativa al desarrollo. Algunas reflexiones económicas y no tan económicas. Política y Sociedad, 2 (52)

Arellano García, C. y Briceño Cruz, M.E. (04.03.2020). Conceden suspensión a comunidades indígenas contra Tren Maya. Recuperado de: https://www.jornada.com.mx/ultimas/politica/2020/03/04/conceden-suspension-acomunidades-indigenas-contra-tren-maya-38|3.html (I6.06.2020)

Bachelet, M. (09.04.20 I9). Declaración de la Alta Comisionada de Naciones Unidas para los Derechos Humanos, Michelle Bachelet, con motivo de su visita a México. Recuperado de: https://www.hchr.org.mx/index.php?option=com k2\&view=item\&id= | 254:declaracion-de-la-alta-comisionada-de-naciones-unidas-para-los-derechoshumanos-michelle-bachelet-con-motivo-de-su-visita-a-mexico\&ltemid=265 (I8.06.2020)

Banco Mundial (2019). Inversión extranjera directa, entrada neta de capital (balanza de pagos, US $\$$ a precios actuales). Obtenido de https://datos.bancomundial.org/indicador/BX.KLT.DINV.CD.WD

Bauman, Z. (2005). Vidas desperdiciadas. La modernidad y sus parias. Barcelona: Editorial Paidós

Basualdo, L., Domenech, E., y Pérez, E. (2019). Territorios de la movilidad en disputa: cartografías críticas para el análisis de las migraciones y las fronteras en el espacio sudamericano. Revista Interdisciplinar da Mobilidade Humana, 57 (27)

Cabrera, S. y Prieto, S. (14.0I.2019). Más allá del Tren y lo Maya: el neoextractivismo con «rostro humano». Recuperado de: $\quad$ https://www.contralinea.com.mx/archivo-revista/2019/0I//4/mas-alla-del-tren-y-lo-maya-elneoextractivismo-con-rostro-humano/ (I8.06.2020)

Capdepont-Ballina, J.L. (2010). Mesoamérica o el Proyecto Mesoamérica: la historia como pretexto. Revista LiminaR. Estudios sociales y humanísticos, 2 (VIII)

Caravana Toxitour México (2020). Informe de la caravana a 6 zonas de sacrificio por devastación ambiental para visibilizar y documentar los impactos socio-ambientales de las empresas transnacionales y el libre comercio en México. México

Centro de Derechos Humanos Fray Bartolomé de las Casas (16.03.2020). Comunidades Mayas rechazan megaproyectos que amenazan la Vida. Recuperado de: https://frayba.org.mx/wp-content/uploads/2020/03/200316 _ Boletin_06_Tren_Maya.pdf (16.06.2020) 
Comisión Económica para América Latina y el Caribe (2020). La Inversión Extranjera Directa en América Latina y el Caribe 2020. Recuperado de: https://www.cepal.org/es/publicaciones/46450-la-inversion-extranjera-directaamerica-latina-caribe-2020 (I 2.12.2020)

Clavijo, I. y Castrejón, D. (2020). El tren de las élites. Empresas beneficiadas y proyectos energéticos en el sureste mexicano. Proyecto sobre Organización, Desarrollo, Educación e Investigación (PODER)

De Sousa Santos, B. (20I4). Derechos humanos, democracia y desarrollo. Bogotá: Centro de Estudios de Derecho, Justicia y Sociedad, Dejusticia

De Sousa Santos, B. y Meneses, M. P. (20I4). Epistemologías del Sur (Perspectivas). Madrid: Akal

Diario Oficial de la Federación (2019). Plan Nacional de Desarrollo 2019-2024. México: Gobierno de México

Echart Muñoz, E. y Villarreal Villamar, M.C. (2018). Resistencias y alternativas al desarrollo en América Latina y Caribe: luchas sociales contra el extractivismo. Relaciones Internacionales, 39

EZLN (I6.03.20I9). Convocatoria a las jornadas de lucha «Zapata vive, Samir vive, la lucha sigue» a I 00 años del asesinato del General Emiliano Zapata Salazar. Recuperado de: http://enlacezapatista.ezIn.org.mx/201 9/03/I6/convocatoriaa-las-jornadas-de-lucha-zapata-vive-samir-vive-la-lucha-sigue-a-100-anos-del-asesinato-del-general-emilianozapata-salazar/ (I 8.06.2020)

Flores, A., Deniau,Y.y Prieto, S. (2019). ElTren Maya. Un nuevo proyecto de articulación territorial en la Península de Yucatán. México: GeoComunes, Consejo Civil Mexicano para la Silvicultura Sostenible

Forbes (2020). World's Billionaires List. The Richest in 2020. Recuperado de: https://www.forbes.com/billionaires/

Front Line Defenders (2019). Front Line Defenders Global Analysis 20 19. Recuperado de: https://www.frontlinedefenders. org/sites/default/files/global_analysis_2019_web.pdf (06.06.2020)

Galtung, J. (2003). Paz por medios pacíficos. Paz y conflicto, desarrollo y civilización. Bilbao: Bakeaz, Gernika Gogoratuz

Gobierno de México (23 de diciembre de 2019). Consulta Libre, revia e Informada sobre el Proyecto de Desarrollo Tren Maya. Presentación de resultados. Disponible en: https:/www.gob.mx/cms/uploads/attachment/file/5 I8708/ presentacion-resultados-consulta-tren-maya-diciembre-2019.pdf

Gobierno de México (2019). Participación democrática y diálogo permanente: vías necesarias para la construcción del Proyecto de Desarrollo Tren Maya. Disponible en: https://www.gob.mx/inpi/es/articulos/participaciondemocratica-y-dialogo-permanente-vias-necesarias-para-la-construccion-del-proyecto-de-desarrollo-trenmaya-230632? idiom $=$ es

Grupo Constituido por CONACYT para el Análisis de Riesgos en los Territorios en los que está proyectado el Tren Maya (GC-TTM) (I2.20I9). Territorios Mayas en el paso del tren: situación actual y riesgos previsibles. Recuperado de: https://www.ccmss.org.mx/wp-content/uploads/Territorios_mayas_en_el_paso_del_tren_ Tr.pdf (06.06.2020)

Gudynas, E. (20|4). Sustentación, aceptación y legitimación de los extractivismos: múltiples expresiones, pero un mismo basamento. Opera, 14

Gutiérrez Rivas, R. y Del Pozo Martínez, E. (2019). De la consulta a la libre determinación de los pueblos. Informe sobre la implementación del derecho a consulta y al consentimiento previo, libre e informado en México. México: Fundación para el Debido Proceso, Instituto de Investigaciones Jurídicas de la UNAM y Fundar

Harvey, D. (2005). El "nuevo" imperialismo: acumulación por desposesión. Buenos Aires: Consejo Latinoamericano de Ciencias Sociales

Herrero, Y. (2019). Introducción: Radicalidad ecosocial y noviolenta frente a la guerra contra la vida. Facilitación Noviolenta de Comunidades para Transiciones Ecosociales

Huanacuni Mamani, F. (20I0). Bien Vivir / Vivir Bien. Filosofia, políticas, estrategias y experiencias regionales andinas. Lima: Coodinadora Andina de Organizaciones Indígenas

Mbembe,A. (2003). Necropolitics. Public Culture, I5

Molinero Gerbeau, Y. y Avallone, G. (2016). Produciendo comida y trabajo baratos: migraciones y agricultura en la ecología-mundo capitalista. Relaciones Internacionales, 33

Molinero Gerbeau, Y. y Avallone, G. (2020). Ecología-mundo, un nuevo paradigma para el estudio de las migraciones internacionales. Empiria. Revista de Metodología de Ciencias Sociales, 46

Montemayor, C. (2000). He venido a contradecir. La cosmovisión de los pueblos indígenas actuales”, en Desacatos. Revista de Ciencias Sociales, 5

Moore, J.W. (20 I6). El fin de la naturaleza barata: o cómo aprendí a dejar de preocuparme por «el» medioambiente y amar la crisis del capitalismo. Relaciones Internacionales, 33

Núñez Rodríguez, V.R. (2020). El despojo financiero: los campesinos como «socios» del Tren Maya. Panamá en Tehuantepec. Colonización ferroviaria del sureste de México, América Latina en Movimiento, 547

Oficina en México del Alto Comisionado de las Naciones Unidas para los Derechos Humanos (19.12.2019). ONU$\mathrm{DH}$ : el proceso de consulta indígena sobre el Tren Maya no ha cumplido con todos los estándares internacionales de derechos humanos en la materia. Recuperado de: https://hchr.org.mx/images/Comunicados/2019/20191219_ ComPrensa_TrenMaya.pdf (I 2.05.2020)

Quijano, A. (2000). El fantasma del desarrollo en América Latina. Revista del CESLA, I

Prieto Díaz, S. (2020). El Tren Maya y las nuevas Fronteras del Sur de México. Panamá en Tehuantepec. Colonización ferroviaria del sureste de México,América Latina en Movimiento, 547

Red Universitaria Anticapitalista (1 2.05.2020). Un tren contra los pueblos mayas. Recuperado en: https://www.youtube. com/watch?v=YcDeCmcvbBg\&t=2833s (1 2.05.2020) 
Sandoval, D. (2020). Tren Maya, Sembrando Vida y Corredor Transístmico. Impactos en el valor de uso territorial de las comunidades indígenas y campesinas. México: Centro de Estudios para el Cambio en el Campo Mexicano

Silva Santisteban, R. (20I7). Mujeres y conflictos ecoterritoriales. Impactos, estrategias, resistencias. Lima: Demus, CMP Flora Tristán, CNDDHH, Entrepueblos y AIETI

Svampa, M. (2008). La disputa por el desarrollo: territorio, movimientos de carácter socio-ambiental y discursos dominantes. En Svampa, M. Cambio de época. Movimientos sociales y poder político. Buenos Aires: Siglo XXI

Teran Mantovani, E. (20I4). Las espirales del debate sobre extractivismo y los nuevos tiempos. Revista Pueblos

Tribunal Permanente de los Pueblos (2014). Sentencia. Libre comercio, violencia, impunidad y derechos de los pueblos en México (20Il-20/4). México

Vargas, M. (I 0.06.2020). Mirándonos en el espejo mexicano. 26 años de libre comercio, paraísos industriales para las empresas, infiernos ambientales para los Pueblos. Recuperado de: https://longreads.tni.org/es/mirandonos-en-el-espejomexicano/\#note2 (I 2.06.2020)

Zibechi, R. (20I4). El estado de excepción como paradigma político del extractivismo. En Composto, C. y Navarro, M.L. (Coord.) Territorios en disputa. Despojo capitalista, luchas en defensa de los bienes comunes naturales y alternativas emancipatorias para América Latina (pp. 76-78). Ciudad de México: Bajo Tierra Ediciones 


\section{RELACIONES INTERNACIONALES}

Revista académica cuatrimestral de publicación electrónica Grupo de Estudios de Relaciones Internacionales (GERI)

Universidad Autónoma de Madrid, España

https://revistas.uam.es/relacionesinternacionales

ISSN 1699 - 3950

f facebook.com/RelacionesInternacionales

3. twitter.com/RRInternacional 